\title{
PENGEMBANGAN MEDIA BELAJAR PUPUH BERBASIS ANDROID
}

\author{
Oleh \\ Gusti Ngurah Wira Satryawan ${ }^{1}$, I Gede Mahendra Darmawiguna ${ }^{2}$, I Made Gede Sunarya ${ }^{3}$ \\ Jurusan Pendidikan Teknik Informatika \\ Universitas Pendidikan Ganesha \\ Singaraja, Bali \\ E-mail: wirasatryawan@gmail.com ${ }^{1}$,igd.mahendra.d@gmail.com ${ }^{2}$, \\ imadegedesunarya@gmail.com ${ }^{3}$
}

\begin{abstract}
ABSTRAK
Pupuh merupakan salah satu dari empat jenis tembang yang ada di Bali. Pupuh digunakan untuk mengutarakan nasehat, cerita kepahlawanan dan perasaan yang biasanya ditampilkan pada dramatari yang berkembang di Bali seperti drama gong, arja maupun Bondres. Media Belajar Pupuh Berbasis Android ini merupakan sebuah media belajar pupuh dengan menggunakan perangkat Android. Penelitian ini bertujuan untuk merancang dan mengimplementasikan rancangan aplikasi Media Belajar Pupuh Berbasis Android.

Pengembangan Media Belajar Pupuh Berbasis Android menggunakan siklus hidup pengembangan perangkat lunak SDLC (Software Development Life Cycle) dengan model waterfall atau model air terjun. Fitur-fitur dalam aplikasi ini bertujuan sebagai media belajar pupuh bagi pengguna dengan menggunakan perangkat Android. Adapun fitur dari aplikasi ini yaitu teori pupuh, uger-uger pupuh, laras pupuh, tembang pupuh dan rekaman pengguna.

Hasil dari penelitian ini yaitu perancangan dan implementasi dari Media Belajar Pupuh Berbasis Android yang telah berhasil dilakukan. Perancangan dilakukan dengan menggunakan model fungsional berupa UML (Unified Modeling Languange). Diimplementasikan dalam bahasa pemrograman Java dengan menggunakan editor Eclipse dan plug-ins ADT (Android Development Tools) serta menggunakan AndEngine sebagai library tambahan. Seluruh kebutuhan fungsional telah berhasil diimplementasikan sesuai dengan rancangan.
\end{abstract}

Kata - kata Kunci: Pupuh, Media Belajar, Android

\begin{abstract}
Pupuh is one of the four types of songs that exist in Bali. Pupuh is used to express advices, stories of heroism and feelings that usually shown on dramatari which is developed in Bali such as drama gong, arja and Bondres. This Media Belajar Pupuh Berbasis Android is a learning media pupuh with an Android device. This research aims to design and implement application design Media Belajar Pupuh Berbasis Android.

Development of the Media Belajar Pupuh Berbasis Android is using the software development life cycle SDLC (Software Development Life Cycle) with the waterfall model. Features in this application are intended as a learning pupuh for users with an Android device. The features of this application are the theory of pupuh, uger-uger of pupuh, tunings of pupuh, songs of pupuh and recordings of the user.

The result of this research is the design and implementation of the Media Belajar Pupuh Berbasis Android that has been successfully carried out. The design is done by using a functional model of the UML (Unified Modeling Language). Implemented in Java programming language using the Eclipse editor and ADT (Android Development Tools) plugins, and also using AndEngine as additional libraries. The entire functional requirements have been successfully implemented in accordance with the design.
\end{abstract}

Pengembangan Media Belajar......(Gusti Ngurah Wira Satryawan ${ }^{1}$, I Gede Mahendra Darmawiguna $^{2}$, I Made Gede Sunarya ${ }^{3}$ ) 
Keywords: Pupuh, Learning media, Android

\section{PENDAHULUAN}

Bali merupakan sebuah pulau kecil yang terletak di tengah-tengah wilayah negara Republik Indonesia. Bali dihuni oleh masyarakat religius yang melahirkan seni-budaya unik dalam kehidupan sehari-hari (S Pendit, 2001). Kebudayaan adalah segala hal yang dimiliki oleh manusia, yang hanya diperolehnya dengan belajar dan menggunakan akalnya (Koentjaraningrat, 1998). Salah satu kerangka kebudayaan adalah kesenian, dimana salah satu jenis kesenian tersebut adalah seni sastra.

Tembang merupakan bagian seni yang dituangkan dalam alunan suara, irama, dan ritme dengan menggunakan laras pelog maupun laras slendro. Tembang yang berkembang dalam masyarakat Bali pada dasarnya dibagi menjadi empat, yaitu: (1) sekar rare, (2) sekar alit, (3) sekar madya dan (4) sekar agung.

Sekar alit disebut juga dengan pupuh, gaguritan atau tembang macapat (maca papatpapat). Dalam belajar menyanyikan pupuh, seseorang harus memahami aturan-aturan yang mengikat sebuah pupuh seperti pada lingsa, guru wilang dan guru dingdong. Di samping aturan tersebut, penembang harus memahami unsur tangga nada, bahasa serta penjiwaan terhadap pupuh tersebut (Budha Gautama, 2007). Cara yang efektif untuk belajar menyanyikan pupuh yaitu dengan sesering mungkin mendengar contoh cara menembangkannya dan dituntun oleh orang yang bisa menembangkan pupuh secara benar. Keterbatasan sumber daya untuk mengajarkan cara matembang pupuh dengan benar menjadi kendala utama dalam proses pembelajaran pupuh.

Selaras dengan kemajuan jaman, pembuatan media berbasis aplikasi yang digunakan untuk membantu dalam proses belajar semakin gencar dilakukan. Seperti penelitian yang dilakukan oleh Pratama Saputro yaitu Multimedia Pembelajaran Tembang Macepat Laras, media berbasis flash ini berisi contoh tembang macepat sunda dengan laras pelog (Saputro, Pratama, 2013).

Mengingat banyaknya pengguna Android dan kehidupan penulis sebagai generasi muda Bali, penulis tertarik untuk mengembangkan suatu media untuk belajar pupuh dengan berbasis Android. Media Belajar Pupuh Berbasis Android yang penulis kembangkan berisikan teori mengenai pupuh serta contoh aturan yang mengikat bait pupuh dan contoh rekaman suara mengenai laras dan tembang pupuh. Nantinya dengan menggunakan media ini, seseorang bisa belajar pupuh tanpa perlu bimbingan yang intensif oleh seseorang yang ahli dalam menembangkan pupuh, sehingga budaya Bali tetap bisa dipertahankan sampai generasi mendatang. 


\section{KAJIAN TEORI}

\section{A. Tembang}

Tembang merupakan bagian seni yang dituangkan dalam alunan suara, irama, dan ritme dengan menggunakan laras pelog dan laras slendro. Hal tersebut dapat menggugah hati atau perasaan sang pendengarnya (Budiyasa dan Purnawan, 1997). Keberadaan tembang di Bali telah ada sejak zaman pra-Hindu. Sedangkan, tanda-tanda kegiatan matembang telah ada sejak zaman pemerintahan Raja Ugrasena sekitar atau tahun 846 M.

\section{B. Pupuh}

Tembang macepat juga sering disebut dengan sekar alit. Istilah tembang macepat diambil dari bahasa jawa yang berarti suatu sistem untuk membaca syair tembang atas empat suku kata. Di Bali tembang macepat juga disebut pupuh yang berarti rangkaian tembang. Selain dipergunakan sebagai alat komunikasi, pupuh juga sering digubah untuk menceritakan suatu kisah atau cerita-cerita rakyat dan disebut gaguritan. Pupuh sebagai alat komunikasi memiliki sifat-sifat yang diekspresikan, dimana ekspresi dari berbagai jenis pupuh berbeda satu sama lain (Budiyasa dan Purnawan, 1997).

Tembang macepat atau pupuh memiliki aturan-aturan atau kaidah yang mengikat sebagai suatu ketentuan dalam membuat ataupun menyanyikan sebuah pupuh, aturan tersebut disebut dengan uger-uger. Uger-uger yang mengikat sebuah pupuh sebagai berikut.

1. Hukum padalingsa yaitu banyaknya baris dalam satu bait tembang.

2. Hukum guru wilang yaitu banyaknya suku kata dalam satu baris tembang.

3. Hukum guru dingdong yaitu huruf vokal atau huruf hidup pada akhir suku kata tiap-tiap baris dalam satu bait tembang.

Nada-nada yang mengikat tembang, baik sekar rare, sekar alit, sekar madya maupun sekar agung adalah laras pelog (patutan gong) dan laras slendro (patutan gender). Pada ilmu musik modern, laras pelog dan laras slendro dikenal dengan nama tangga nada pentatonik.

\section{Android}

Android merupakan sebuah sistem operasi untuk perangkat mobile berbasis Linux yang mencangkup sistem operasi, middleware dan aplikasi (Safaat dan Nazruddin, 2012). Android menyediakan platform terbuka bagi para pengembang untuk menciptakan aplikasi mereka. Android Inc. adalah sebuah perusahaan perangkat hardware ponsel yang terletak di Palo Alto, California Amerika Serikat. Sejak Juli 2000, Android bekerjasama dengan perusahaan Google Inc untuk mengembangkan sistem operasi untuk ponsel.

Android dipuji sebagai sistem operasi mobile yang lengkap, terbuka dan bebas (Safaat dan Nazruddin, 2012). Android Saat ini merupakan sistem operasi mobile yang paling

Pengembangan Media Belajar......(Gusti Ngurah Wira Satryawan ${ }^{1}$, I Gede Mahendra Darmawiguna $^{2}$, I Made Gede Sunarya ${ }^{3}$ ) 
banyak digunakan (Utomo dan Priyo, 2012). Versi terbaru Android saat ini yaitu Kitkat, dimana codename atau penamaan dari versi Android menggunakan nama makanan atau minuman pembuka.

\section{Eclipse}

Eclipse adalah sebuah IDE (Integrated Development Environment) untuk mengembangkan perangkat lunak dan dapat dijalankan di semua platform (platformindependent). Eclipse pada saat ini merupakan salah satu IDE favorit dikarenakan gratis dan open source. Kelebihan dari Eclipse yang membuatnya populer fasilitas plug-in yang dimilikinya, dengan menggunakan plug-in membuat Eclipse dapat digunakan untuk mengembangkan pemrograman selain Java untuk berbagai macam keperluan. Pengembangan aplikasi Android menggunakan Eclips, menggunakan bahasa Java dan plug-in Android Development Tools (ADT). Aplikasi Android yang telah dibuat di Eclipse dapat dijalankan menggunakan AVD (Android Virtual Device), sehingga kita tidak harus memerlukan perangkat Android asli (Safaat dan Nazruddin, 2012).

\section{E. AndEngine}

AndEngine merupakan game engine yang memfokuskan pada pembuatan game berbasis 2D di platform Android. Karena sudah berupa engine maka, pembuat game akan dipermudah dengan disediakan banyak fitur-fitur untuk membuat game. Berikut beberapa fitur yang disediakan oleh AndEngine seperti resolusi, landscape/potrait, sprite, animasi, pengecekan tubrukan (collision) texture, font, event touch dan accelerometer, particle dan lain-lain (Wismono, dan Nugroho, 2012).

\section{F. Media Belajar}

Media berasal dari bahasa Latin dan merupakan bentuk jamak dari kata medium yang secara harfiah berarti perantara atau pengantar (Sandiman dkk, 1986). belajar bukanlah suatu tujuan tetapi merupakan suatu proses untuk mencapai tujuan. Belajar bukan hanya mengingat, akan tetapi mengalami atau mengetahui. Sehingga media belajar merupakan suatu perantara ataupun alat bantu yang digunakan seseorang dalam proses belajar.

\section{METODOLOGI}

\section{A. Analisis Masalah dan Usulan Solusi}

Berdasarkan analisis yang penulis lakukan, pupuh merupakan salah satu kesusastraan Bali dan bagian dari tembang. Pupuh disebut juga tembang macepat, sekar alit, atau geguritan. Dalam mempelajari pupuh, seseorang harus memahami aturan-aturan yang mengikat sebuah pupuh seperti pada lingsa, guru wilang dan guru dingdong. Di samping aturan tersebut, penembang harus memahami unsur tangga nada, bahasa serta penjiwaan 
terhadap pupuh tersebut. Pupuh, sebagai salah satu kebudayaan Bali sudah sepatutnya untuk diketahui dan dipelajari oleh generasi muda Bali.

Android merupakan sebuah sistem operasi untuk perangkat mobile berbasis Linux dan bersifat open source. Open source artinya seorang pengembang akan dapat membuat aplikasi sesuai keinginan, lebih dari itu bahkan dapat menjual aplikasi yang dibuat tanpa harus membayar lisensi ke produsen atau vendor tertentu. Salah satu perusahan media, Millenial Media, menyebutkan tentang penggunaan platform mobile bahwa pada akhir tahun 2011, Android diketahui sebagai sistem operasi mobile yang paling banyak digunakan (Utomo dan Priyo, 2012).

Ketertarikan penulis untuk mengembangkan suatu media belajar pupuh dengan berbasis Android berlandaskan banyaknya pengguna Android dan jiwa serta tekad penulis sebagai generasi muda Bali untuk melestarikan budayanya. Media Belajar Pupuh Berbasis Android yang penulis kembangkan berisikan teori mengenai pupuh serta contoh aturan yang mengikat bait pupuh dan contoh rekaman suara mengenai laras dan tembang pupuh. Sehingga aplikasi ini nantinya berguna bagi masyarakat umum yang ingin belajar menembangkan pupuh.

\section{B. Analisis Perangkat Lunak}

1. Kebutuhan Perangkat Lunak

Media Belajar Pupuh Berbasis Android ini dirancang agar dapat mengimplementasikan kebutuhan fungsional sebagai berikut :

a. Menampilkan menu utama yang terdiri dari menu teori, menu uger-uger, menu laras, menu tembang, menu rekaman dan menu tentang.

b. Menampilkan teori pupuh.

c. Menampilkan uger-uger pupuh.

d. Memutar suara dari laras pupuh.

e. Memutar suara dari tembang pupuh.

f. Memutar rekaman suara.

g. Menampilkan tentang aplikasi.

h. Memiliki fitur mengunduh tembang pupuh .

i. Memiliki fitur menghapus tembang pupuh.

j. Memiliki fitur merekam suara.

k. Memiliki fitur mengelola rekaman suara.

Adapun kebutuhan non-fungsional dari aplikasi yang dikembangkan sebagai berikut :

a. Aplikasi dibuat user friendly baik pada tampilan serta kemudahan menggunakannya.

b. Rekaman suara dari laras dan tembang pupuh berkualitas baik.

2. Tujuan Pengembangan Perangkat Lunak

Pengembangan Media Belajar......(Gusti Ngurah Wira Satryawan ${ }^{1}$, I Gede Mahendra Darmawiguna $^{2}$, I Made Gede Sunarya ${ }^{3}$ ) 
Aplikasi ini dikembangkan sebagai media bagi masyarakat yang ingin belajar mengenai teori dan tembang pupuh. Aplikasi ini juga diharapkan dapat melakukan proses sebagai berikut.

a. Aplikasi dapat menampilkan menu utama yang terdiri dari menu teori, menu uger-uger, menu laras, menu tembang, menu rekaman dan menu tentang.

b. Aplikasi dapat menampilkan teori pupuh.

c. Aplikasi dapat menampilkan uger-uger pupuh.

d. Aplikasi dapat memutar suara dari laras pupuh.

e. Aplikasi dapat memutar suara dari tembang pupuh.

f. Aplikasi dapat memutar rekaman suara.

g. Aplikasi dapat menampilkan tentang aplikasi.

h. Aplikasi dapat mengunduh tembang pupuh.

i. Aplikasi dapat menghapus tembang pupuh .

j. Aplikasi dapat merekam suara.

k. Memiliki fitur mengelola rekaman suara.

3. Masukan dan Keluaran Perangkat Lunak

Masukkan dari aplikasi yang dikembangkan sebagai berikut.

a. Touch atau sentuhan pada layar.

b. Suara yang direkam saat fitur merekam.

Keluaran dari Media Belajar Pupuh Berbasis Android sebagai berikut.

a. Tampilan teori dan uger-uger pupuh.

b. Suara laras dan tembang pupuh.

c. Suara dari hasil rekaman pengguna.

4. Model Fungsional Perangkat Lunak

Dalam pengembangan aplikasi ini, peneliti menggunakan dua macam diagram yaitu use-case diagram dan activity diagram.

a. Use Case Diagram

Use Case Diagram merupakan diagram yang menggambarkan actor (pengguna atau sistem lain), use case (deskripsi fungsi dari sebuah sistem) dan relasinya (Haviluddin, 2011). 


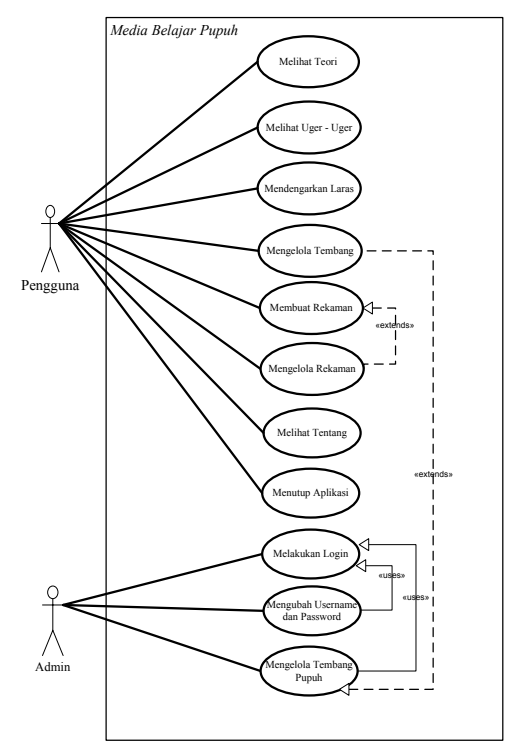

Gambar 1. Use Case Diagram

\section{b. Activity Diagram}

Activity diagram menggambarkan kegiatan diagram alur kerja atau aktivitas dari sistem (Haviluddin, 2011). Activity diagram menggambarkan aktivitas dalam sistem yang sedang dirancang, bagaimana masing-masing alir berawal, decision yang mungkin terjadi, dan bagaimana aktivitas itu berakhir. Activity diagram juga dapat menggambarkan proses paralel yang mungkin terjadi pada beberapa eksekusi yang dijalankan dari sebuah sistem.

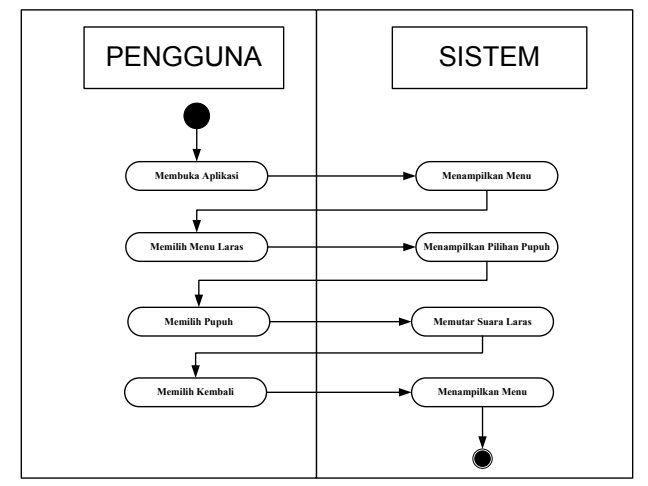

Gambar 2. Activity Diagram Mendengarkan Laras

Pengembangan Media Belajar......(Gusti Ngurah Wira Satryawan ${ }^{1}$, I Gede Mahendra Darmawiguna $^{2}$, I Made Gede Sunarya ${ }^{3}$ ) 


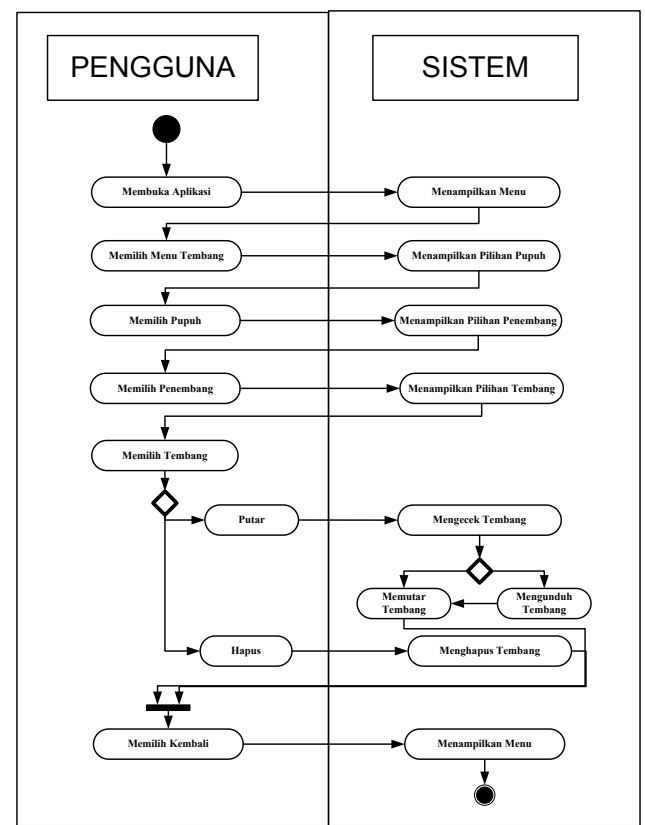

Gambar 3. Activity Diagram Mengelola Tembang

C. Perancangan Perangkat Lunak

1. Batasan Perancangan Perangkat Lunak

Adapun batasan perancangan dari pengembangan aplikasi ini, yaitu Aplikasi ini dirancang memuat 10 jenis pupuh yang umum terdapat di Bali. Pupuh tersebut yaitu : (1) pupuh mijil, (2) pupuh pucung, (3) pupuh ginanti, (4) pupuh ginada, (5) pupuh maskumambang, (6) pupuh sinom, (7) pupuh semarandana, (8) pupuh durma, (9) pupuh dangdang gula, (10) pupuh pangkur.

2. Perancangan Struktur Navigasi

Struktur navigasi memberikan kemudahan dalam menganalisa keinteraktifan seluruh objek dalam aplikasi dan bagaimana pengaruh keinteraktifannya terhadap pengguna (Haviluddin, 2011).

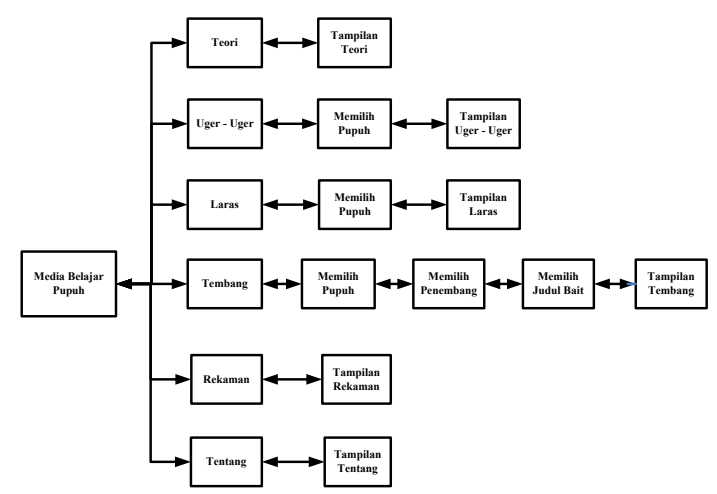

Gambar 4. Struktur Navigasi Perangkat Lunak 
Pada Gambar 4 dapat diketahui Struktur Navigasi aplikasi yang dibangun, bahwa aplikasi Media Belajar Pupuh memiliki enam menu utama yaitu : Teori, Uger-Uger, Laras, Tembang, Rekaman, dan Tentang.

\section{PEMBAHASAN}

\section{A. Implementasi Perangkat Lunak}

1. Lingkungan Implementasi Perangkat Lunak

Implementasi Media Belajar Pupuh Berbasis Android dilakukan pada lingkungan perangkat lunak yaitu:

a. Eclipse Version: 4.2.1

b. Plugins ADT (Android Development Tools) Version: 22.0.5

c. AndEngine GLES2

d. Adobe Photoshop CS 3

e. Audacity 2.0.4

Adapun lingkungan perangkat kerasnya yaitu sebuah laptop dengan spesifikasi sebagai berikut.

a. Monitor 14,1 inchi dengan resolusi 1366 x 768

b. Memori 6 GB RAM dan harddisk 750 GB

c. Processor Intel ${ }^{\circledR}$ Core $^{\mathrm{TM}}$ i5 $2.4 \mathrm{Ghz}$

Perangkat keras lainnya yaitu sebuah perangkat Android dengan spesifikasi sebagai berikut.

a. Android 4.2.2 (Jelly Bean)

b. Layar 4 inchi dengan resolusi $480 \times 782$

c. RAM 1 GB

d. Processor Qualcomm Snapdragon S4 $1.03 \mathrm{GHz}$

e. GPU Krait

2. Batasan Implementasi Perangkat Lunak

a. Processor ARM-v7a

b. GPU kelas mid-end

3. Implementasi Antarmuka Perangkat Lunak

Implementasi antarmuka dilakukan sesuai dengan rancangan antarmuka yang telah dibuat sebelumnya.

a. Implementasi Antarmuka Menu Utama

Pengembangan Media Belajar......(Gusti Ngurah Wira Satryawan ${ }^{1}$, I Gede Mahendra Darmawiguna $^{2}$, I Made Gede Sunarya ${ }^{3}$ ) 


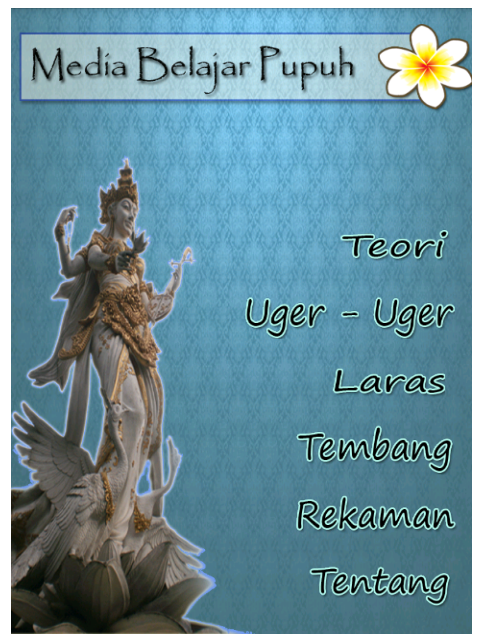

Gambar 5. Implementasi Antarmuka Menu Utama

\section{B. Pengujian Perangkat Lunak}

1. Tujuan Pengujian Perangkat Lunak

Tujuan pengujian aplikasi Media Belajar Pupuh Berbasis Android, yaitu:

a. Menguji penggunaan aplikasi Media Belajar Pupuh Berbasis Android pada perangkat Android yang berbeda.

b. Menguji kebenaran proses aplikasi Media Belajar Pupuh Berbasis Android.

c. Menguji kelayakan Media Belajar Pupuh Berbasis Android sebagai media yang dapat membantu belajar pupuh, khususnya pupuh yang ada di Bali.

d. Menguji kualitas suara dan musik yang dihasilkan aplikasi Media Belajar Pupuh Berbasis Android.

2. Perancangan Kasus Uji Pengujian Perangkat Lunak

Pada tahap ini dideskripsikan secara mendetail bentuk uji kasus yang akan dilaksanakan dan telah disesuaikan dengan tujuan pengujian dan tata ancang pengujian yang telah ditetapkan. Uji kasus dibuat selengkap mungkin agar hasil pengujian sesuai dengan keadaan sistem sebenarnya. Terdapat empat kasus uji yang dirancang sesuai dengan tujuan pengujian perangkat lunak yang digambarkan dengan angket pengujian.

3. Pelaksanaan Pengujian Perangkat Lunak

Pengujian perangkat lunak Media Belajar Pupuh Berbasis Android dilakukan oleh sepuluh orang yang berbeda dan menggunakan beberapa perangkat Android dengan merk dan spesifikasi yang berbeda. Pengujian dilaksanakan pada hari dan tempat yang berbeda dimana masyarakat umum sebagai penguji aplikasi ini.

Evaluasi Hasil Pengujian Perangkat Lunak

Aplikasi Media Belajar Pupuh Berbasis Android dapat dijalankan pada semua perangkat Android yang diujikan sesuai dengan kebutuhan minimum aplikasi yang telah ditetapkan. Seluruh fitur yang terdapat pada Media Belajar Pupuh Berbasis Android dapat dijalankan dan tidak terjadi error. 
Aplikasi Media Belajar Pupuh Berbasis Android mampu memberikan informasi mengenai teori, laras, maupun tembang dari pupuh. Terbukti dari sepuluh orang penguji seluruhnya memberikan penilaian baik terhadap kelayakan aplikasi ini sebagai media belajar pupuh.

Kualitas suara dari sepuluh jenis suara laras pupuh, satu orang memberikan penilaian sedang untuk kualitas suara laras sinom. Dua orang penguji memberikan penilaian sedang untuk kualitas suara laras mijil, laras ginanti, laras ginada, dan laras semarandana. Tiga orang penguji memberikan penilaian sedang untuk kualitas suara laras pucung, selebihnya penguji memberikan penilaian baik. Untuk suara tembang pupuh, dua orang memberikan penilaian sedang untuk kualitas suara tembang semarandana, selebihnya penguji memberikan penilaian baik. Untuk suara rekaman dua orang memberikan penilaian sedang, selebihnya penguji memberikan penilaian baik.

\section{SIMPULAN DAN SARAN}

Berdasarkan penelitian dan pengembangan aplikasi Media Belajar Pupuh Berbasis Android yang telah dilakukan maka, diperoleh kesimpulan sebagai berikut.

a. Media Belajar Pupuh Berbasis Android merupakan sebuah media belajar mengenai pupuh, khususnya pupuh yang ada di Bali yang dijalankan pada platform Android.

b. Perancangan Media Belajar Pupuh Berbasis Android telah berhasil dilakukan dengan menggunakan model fungsional berupa UML (Unified Modeling Languange) yaitu dengan menggunakan use case diagram, activity diagram, dan sequence diagram.

c. Media Belajar Pupuh Berbasis Android telah berhasil diimplementasikan sesuai dengan rancangan yang telah dibuat sebelumnya. Media Belajar Pupuh Berbasis Android diimplementasikan menggunakan bahasa pemrograman Java dengan editor Eclipse versi 4.2.1 dan plug-ins ADT (Android Development Tools) versi 22.0.5 serta menggunakan AndEngine sebagai library tambahan.

d. Fitur dari Media Belajar Pupuh Berbasis Android adalah menampilkan teori serta memberikan contoh suara laras dan tembang dari sepuluh pupuh yang ada di Bali.

e. Media Belajar Pupuh Berbasis Android dapat berjalan pada perangkat Android yang sesuai dengan spesifikasi minimal yang telah ditetapkan sebelumnya.

Pengembangan Media Belajar......(Gusti Ngurah Wira Satryawan ${ }^{1}$, I Gede Mahendra Darmawiguna $^{2}$, I Made Gede Sunarya ${ }^{3}$ ) 


\section{DAFTAR PUSTAKA}

S Pendit, Nyoman.2001.Membangun Bali.Denpasar : PT. BP Denpasar.

Koentjaraningrat.1998.Pengantar Antropologi II.Jakarta : PT Rineka Cipta.

Budha Gautama, Wayan.2007.Penuntun Pelajaran Gending Bali. Denpasar: CV.Kayumas Agung.

Saputro, Pratama.2013.Multimedia Pembelajaran Tembang Macapat Laras. Fakultas Ilmu Komputer : Universitas Dian Nuswantoro Semarang.Wismono, Andi Taru Nugroho. 2012.

Budiyasa, Nyoman dan Ketut Purnawan. 1997. Kesenian Daerah dan Sosial Budaya. Denpasar: PT. Intan Pariwara.

Safaat H, Nazruddin.2012.Android.Bandung : Informatika.

Utomo, Eko Priyo.2012.From Newbie to Advanced.Yogyakarta : ANDI.

Wismono, Andi Taru Nugroho. 2012. Cara Mudah Membuat Game di Android. Yogyakarta : ANDI

Sandiman, Arief S dkk.1986.Media Pendidikan.Jakarta : PT Rajagrafindo Persada.

Haviluddin.2011.Memahami Penggunaan UML (Unified Modelling Language). Jurnal Informatika Mulawarman, Volume 6, Nomor 1. 